\title{
Elise Crull, Guido Baccagaluppi (Eds.): Grete Hermann: Between Physics and Philosophy. (Studies in the History and Philosophy of Science). Springer: Dordrecht 2016, 281 pp., 106,99€ (hardcover), ISBN 9789402409703
}

\section{Michael Drieschner ${ }^{1}$}

Published online: 27 November 2020

(C) The Author(s) 2020

Grete Hermann must have been a fascinating woman: After studies in mathematics, physics, and philosophy at the University of Göttingen she obtained a doctorate degree in mathematics under the supervision of Emmy Noether, who would later became famous for her work on the relation between conserved quantities and symmetries. Already in Göttingen she met Leonard Nelson, a Neo-Kantian philosopher, and became his collaborator and "disciple"- though a critical one. In the 1930s she participated in the debate about the then new quantum mechanics. In order to get firsthand information she went for some time to work in Heisenberg's institute at the University of Leipzig.

Besides those academic activities, she was strongly engaged politically and pedagogically as a socialist. With her political friends, she tried to organize a common front of the socialist and communist parties in order to prevent the Nazis from ruling Germany-an attempt that, as we know, failed. It was Leonard Nelson who encouraged all his followers to realize their philosophical insights in practical life. So Grete Hermann worked, besides her socialist political commitment, in pedagogical initiatives. She worked with others in founding and running a boarding school ("Walkemühle") for education of adults as well as children in a peaceful atmosphere.

After the Nazis assumed power, eventually she had to flee with parts of the boarding school, first to Denmark and later to England. After the war she went back to Germany and continued her pedagogical and political work, then mainly connected with the labour union and the Social Democratic Party. There she was one of those who put up the new party program for post-war Germany. Finally, she had a permanent position for pedagogy at the University of Bremen.

The edition 'Grete Hermann-Between Physics and Philosophy' by Elise Crull and Guido Baccagaluppi reviewed here deals mainly with Hermann's work on the philosophy of quantum mechanics. In its part IV it presents three key texts translated into English: A letter from Gustav Heckmann, a friend of hers, of December 1933 dealing with a long discussion he had with Heisenberg about her work, and two papers by Hermann herself on quantum mechanics: 'Determinism and Quantum Mechanics' (1933) and

Michael Drieschner

michael.drieschner@rub.de

1 Institut für Philosophie I, Ruhr-Universität Bochum, Bochum, Germany 
'Natural-Philosophical Foundations of Quantum Mechanics' (1935), all translated into English by the editors. The first of her own texts is an unpublished draft she had sent to Dirac and Heisenberg, among others; the second is her main publication on philosophical questions of quantum mechanics. Those texts comprise the final about 50 pages of the volume.

Part I of the volume, about 50 pages as well, titled "Hermann's Background," consists of three papers:

1. A biographical sketch by Inge Hansen-Schaberg, which itself is fascinating to read just because of the inspiring life of Hermann. It shows a mathematician, philosopher, teacher, and political activist who can, even after about 100 years, serve as a model for eager young people of today. Her achievements in quantum mechanics, regardless of those in other fields, command respect considering the early stage of quantum mechanics she found in her studies and, for example, during her visit to Leipzig. At that time she contributed sharp analyses of logical points as well as of misunderstandings of the development of quantum mechanics. Carl Friedrich von Weizsäcker, physicist and philosopher, one of the first scholars who dealt with quantum mechanics, had an extended correspondence with Hermann in the 1930s. He later wrote to Hermann in a letter of 1956: "The paper you wrote 20 years ago about the philosophical meaning of quantum mechanics was, to my mind, the first fully valid answer which the then young theoretical atomic physics got from the side of philosophy. And not much followed from others since." (Translation mine)

2. 'Grete Hermann as a Philosopher' by Fernando Leal. He deals mainly with the philosophical tradition Hermann finds herself in, i.e. the line from Kant to Fries to Nelson and to Hermann herself. He characterizes what Hermann got from Nelson as the principle of "walking the talk", i.e., like Socrates, finding what the right thing is, and putting that to life-again like Socrates who "put the life of his partners to test". Among other questions, he discusses Hermann's position on the relation between causes and reasons.

3. 'Understanding Hermann's Philosophy of Nature' by Julia Paparo. She, again, deals with the Neo-Kantian tradition, especially from the point of view of quantum mechanics. There is a section on 'The Friesian Hermann', where Paparo describes her argument against the view that according to quantum mechanics causality has to be abandoned; Hermann here carries on the tradition of distinguishing between the principle of causality and the law of causation. In a later section, also titled 'Hermann's Philosophy of Nature', Paparo emphasizes the difference between Hermann's and Nelson's view, among others Hermann's criticism of Nelson's "absolutism".

Part II of the book, the longest, of almost 100 pages, is titled "Hermann on Quantum Mechanics" and contains seven papers that deal mainly with her pioneering paper of 1935 on 'Natural-Philosophical Foundations of Quantum Mechanics' that is, as mentioned, reprinted in English in Part IV.

4. "Convergence of Transcendental Philosophy and Quantum Mechanics" by Léna Soler deals with Hermann's analysis of causality in transcendental view on quantum mechanics, and how Hermann develops her opinion on deterministic causality even in quantum mechanics, albeit only in retrospective. Soler mentions, as other contributors, the fact that Hermann was the first to point out the flaw in the famous refutation of hiddenvariable theories by J. v. Neumann - and that this discovery was ignored at the time. 
(This issue is taken up again in paper 7: "Challenging the gospel ..." by Michiel Seevinck.)

5. Thomas Filk deals with Hermann's reception of the doctoral thesis of C. F. von Weizsäcker (under the guidance of W. Heisenberg) about the measurement of an electron with a gamma-ray microscope. Filk emphasizes Hermann's focus on questions that came up again in modern discussions, namely, among others, the question of entangled objects, of "delayed choice" between complementary possibilities, and questions that were taken up later in the famous "EPR" paper of Einstein with his collaborators.

6. Mélanie Frappier deals as well with the "Microscope Experiment" of Weizsäcker's dissertation. Frappier discusses in this paper Heisenberg's introduction of the indeterminacy relations in his 1927 paper and Popper's critique of Heisenberg in his book Logik der Forschung of 1935 (printed in English from 1959 on, with additions by Popper, as Logic of Scientific Discovery), (where Frappier calls Popper "another heir of Nelson's Socratic method"). Frappier emphasizes again the importance, according to Nelson and Hermann, of the experimental setup.

7. Michiel Seevinck again analyses Hermann's 1935 refutation of von Neumann's "proof". He compares her refutation with John S. Bell's much later one of 1966, and calls the latter "deeper"- small wonder after so much more discussion about quantum mechanics. Additionally, Seevinck deals with possible reasons for the fact that Hermann's refutation has almost not been recognized at all, as for instance, Hermann being young, a woman and an outsider to the discussion among physicists. Last but not least, there was the political situation that forced her to hide at the time and later even to emigrate. All these facts were important in the year 1935, when her paper was published!

8. The editors discuss the importance of Hermann's "lost" manuscript of 1933 on quantum mechanics (that turned out not to be lost at all, after a copy was found in Dirac's papers, but that was only after a workshop on Hermann in 2012). The editors compare that manuscript with Hermann's 1935 paper in detail, and they quote what Heckmann wrote in his letter of 1933 to Hermann (the letter reprinted in section IV, as mentioned above) about its reception by Heisenberg, who said according to Heckmann: "In substance, she is certainly wrong" but "a fabulously clever woman".

9. This chapter is a comparison by Baciagaluppi between "Bohr's Slit and Hermann's Microscope". He analyses again Hermann's discussion of the gamma-ray microscope treatment by Weizsäcker, and compares it with Bohr's analysis of a thought experiment with a suspended slit, where electrons pass whose position and momentum could be measured by measurements of the slit apparatus. Both are important thought experiments from early discussions about the interpretation of quantum mechanics. Bacciagaluppi gives a painstaking discussion of conceptual as well historical aspects of these experiments.

10. Crull discusses thoroughly the "Relative Context of Observations" as treated by Hermann. She highlights an aspect that was not mentioned so far, namely the continuing importance of the "relative context" in Hermann's 1935 paper. According to Crull, this, not the continuing causality, is the leading philosophical idea of Hermann's paper.

Part III reproduces discussions on the occasion of the Grete Hermann workshop held at the University of Aberdeen in May 2012.

11. This chapter starts with a panel discussion among Dieter Krohn, Rene Saran, and Fernando Leal. The participants say a few words about themselves, and mainly about the history of the political work of Grete Hermann and her associates, especially in connection to the fight against Hitler and his followers. Other anecdotes from her 
life are reported, to which other participants of the workshop contribute. The whole discussion gives a lively picture of what working with Grete Hermann was like.

12. The general discussion reproduced in this chapter is partly about why Hermann's thinking did not have much impact on contemporary discussions. Other subjects are on philosophical, psychological, and ethical questions. The participants discuss questions none of them was able to answer, as, for example, why Hermann did not work with Heisenberg and Weizsäcker for some time after the war, how she originally had planned and prepared? Why did she not like the university atmosphere of post-war Germany, so that she never seemed to consider a university position for herself?-Even though those questions could not be answered in the discussions of that workshop of 2012, it is interesting to see them being discussed by those participants who gained more background knowledge through their studies of Hermann's work and history. Some of the participants mention a judgment by Hermann, being a student of Nelson, that during the Nazi time many Germans, especially scholars who were anti-Nazi at heart, tried to live within the hostile world on some kind of island, not touched by the awful world outside. Hermann thought that such a position could not be justified; you had to decide clearly, according to Hermann: For or against! — At the end the participants discuss questions like: "Why didn't Hermann get more support from the scientists who knew her and her work, like Heisenberg and Weizsäcker?" Even though questions like these are more or less psychological, their discussion provides some insight into the conditions of scientific work in Germany in the time around World War II.

Let me summarize this volume for you: It gives a fascinating picture of a woman who was highly gifted mathematically, philosophically and ethically, among others in the beginnings of quantum mechanics, and who was involved in a very special way in the context of German history before, during, and after World War II. She certainly deserves to be better known by the younger generation than she is at present. Additionally this volume gives impressions about German and European history that cannot be found elsewhere.

Funding Open Access funding enabled and organized by Projekt DEAL.

Open Access This article is licensed under a Creative Commons Attribution 4.0 International License, which permits use, sharing, adaptation, distribution and reproduction in any medium or format, as long as you give appropriate credit to the original author(s) and the source, provide a link to the Creative Commons licence, and indicate if changes were made. The images or other third party material in this article are included in the article's Creative Commons licence, unless indicated otherwise in a credit line to the material. If material is not included in the article's Creative Commons licence and your intended use is not permitted by statutory regulation or exceeds the permitted use, you will need to obtain permission directly from the copyright holder. To view a copy of this licence, visit http://creativecommons.org/licenses/by/4.0/.

Publisher's Note Springer Nature remains neutral with regard to jurisdictional claims in published maps and institutional affiliations. 